P0156

\title{
VALIDATION OF THE SPATIAL BRIGHTNESS ESTIMATION FORMULA IN OFFICES WITH WINDOWS
}

\author{
Yusuke Yonekura et al. \\ DOI 10.25039/x46.2019.PO156 \\ from \\ CIE x046:2019 \\ Proceedings \\ of the \\ 29th CIE SESSION \\ Washington D.C., USA, June 14 - 22, 2019 \\ (DOI 10.25039/x46.2019)
}

The paper has been presented at the 29th CIE Session, Washington D.C., USA, June 14-22, 2019. It has not been peer-reviewed by CIE.

(C) CIE 2019

All rights reserved. Unless otherwise specified, no part of this publication may be reproduced or utilized in any form or by any means, electronic or mechanical, including photocopying and microfilm, without permission in writing from CIE Central Bureau at the address below. Any mention of organizations or products does not imply endorsement by the CIE.

This paper is made available open access for individual use. However, in all other cases all rights are reserved unless explicit permission is sought from and given by the $\mathrm{CIE}$.

CIE Central Bureau

Babenbergerstrasse 9

A-1010 Vienna

Austria

Tel.: +43 17143187

e-mail: ciecb@cie.co.at

www.cie.co.at 


\title{
VALIDATION OF THE SPATIAL BRIGHTNESS ESTIMATION FORMULA IN OFFICES WITH WINDOWS
}

\author{
Yonekura, Y. ${ }^{1}$, Yoshizawa,N. ${ }^{1}$, Tamura, H. ${ }^{1}$, Kage, $\mathrm{H}^{2}$, Harimoto, K. ${ }^{2}$ \\ ${ }^{1}$ Tokyo university of science, Tokyo, JAPAN, ${ }^{2}$ Taisei Corporation, Tokyo, JAPAN \\ omhyonex1107@gmail.com
}

DOI 10.25039/x46.2019.PO156

\begin{abstract}
In recent years daylight harvesting has been one of the promising systems to reduce lighting energy consumptions. Usually in this system the lighting environment is taken into consideration by securing the horizontal surface illuminance on the desktop using photosensors on the ceiling, however, it has become clear in some studies that the quality of the lighting environment does not always link with the desktop illuminance, and luminance distribution at the occupant's eye or vertical illuminances are more important for evaluating the lighting qualities. Therefore, in this research, we aim to develop a new method for daylight harvesting systems by measuring ceiling and window luminance using simple photosensors. The goal of this system is to secure appropriate spatial brightness in the office space and to improve energy efficiency performance at the same time. In this paper simple formulae for estimating spatial brightness in offices with windows were obtained.
\end{abstract}

Keywords: Spatial brightness, Ceiling surface luminance, Window surface luminance, Offices

\section{Background}

In recent years, daylight harvesting has been one of the promising systems to reduce lighting energy consumptions. Usually in this system the lighting environment is taken into consideration by securing the horizontal surface illuminance on the desktop using photosensors on the ceiling, however, it has become clear in some studies that the quality of the lighting environment does not always link with the desktop illuminance, and luminance distribution at the occupant's eye or vertical illuminances are more important for evaluating the lighting qualities. Therefore, in this research, we aim to develop a new method for daylight harvesting systems by measuring wall, ceiling and window luminance using simple photosensors. The goal of this system is to secure appropriate spatial brightness in the office space and to improve energy efficiency performance at the same time.

\section{Experiment Method}

\subsection{Experiment in a small office}

\subsubsection{Outline of the space}

The first experiment was done at a small office room of $4.3 \mathrm{~m}$ in width, $9.7 \mathrm{~m}$ in depth and $2.7 \mathrm{~m}$ in height. It had a window whose size is $3.9 \mathrm{~m}$ in width, $2.0 \mathrm{~m}$ in height on the east side. The inner reflectance is $12 \%$ for the floor surface, $49 \%$ for the wall surface and $77 \%$ for the ceiling surface. Dimmable 25 square ceiling lights for ambient lighting (colour temperature: 4000K) were installed in the experimental space, and 12 lights of them were switched on during the experiment.

12 subjects in the early 20's participated in this experiment. The experimental factors and their levels are as follows: 1) Weather conditions - clear/cloudy, 2) Time period in one day morning/afternoon/night, 3) Venetian blind tilt angle - 0 degree/45 degree/closed, 4) Artificial lighting intensity $-200 / 400 / 750$ lux on the desktop at the centre of the room. There were 54 lighting conditions in total. Illuminance loggers (TR-74U) measured the vertical eye illuminance at the viewpoint of the subjects and the desktop illuminance at the evaluation points at intervals of 5 seconds. 


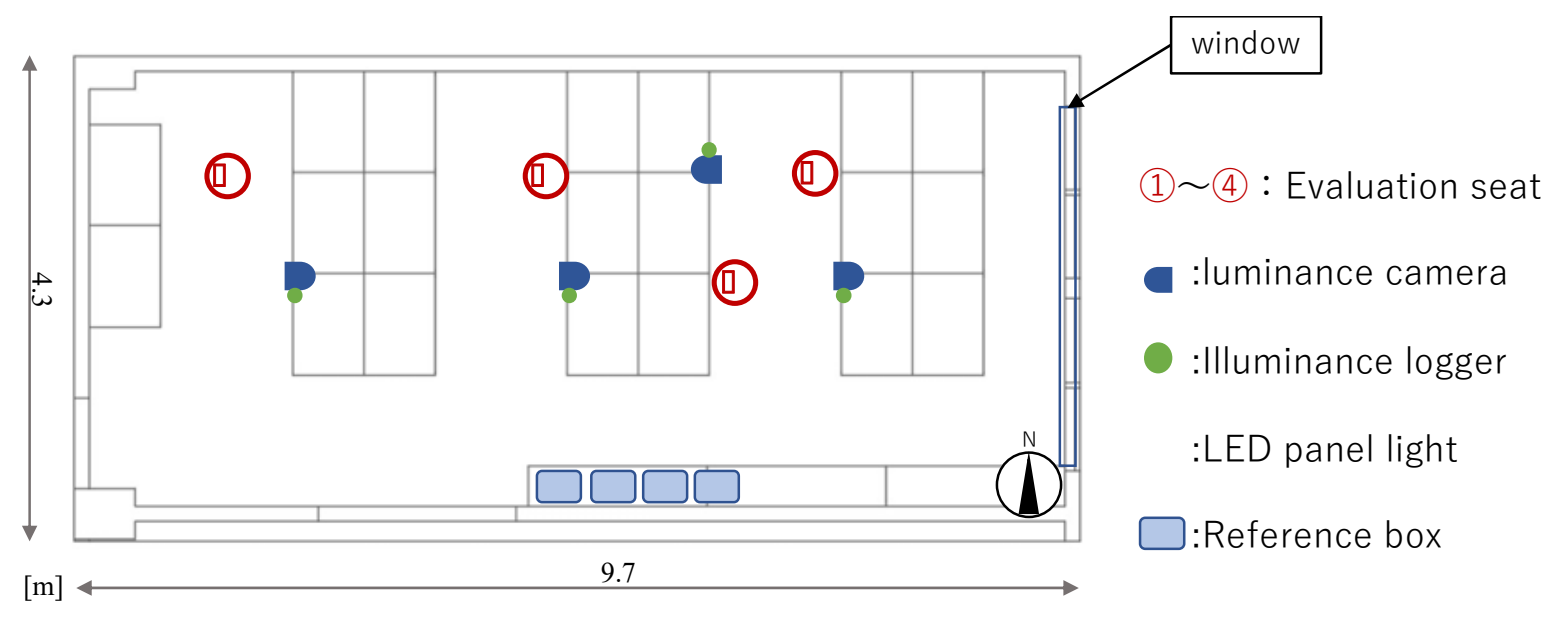

Figure 1 - Drawing of the small office

\subsubsection{Evaluation method}

Subjects evaluated the spatial brightness in the office space by using magnitude estimation method (ME method) comparing to the brightness in the reference box. The reference box was $1 / 8$ scale model of a general small office. The inner reflectance of reference box was set to $12 \%$ for the floor surface, $48 \%$ for the wall surface, and $77 \%$ for the ceiling surface, and the illuminance at the virtual level of $80 \mathrm{~cm}$ above the floor was $3001 x$. The subject observed the front wall and the front area in the reference space. The reference space was observed for 30 seconds, and its spatial brightness was memorized. After that, subjects moved to the evaluation seats in the experimental room. The viewpoint was set at $120 \mathrm{~cm}$ in height from the floor, facing the window. The subject evaluated the brightness of the experimental space above display with a positive integer comparing with the reference box of which brightness was 100 .

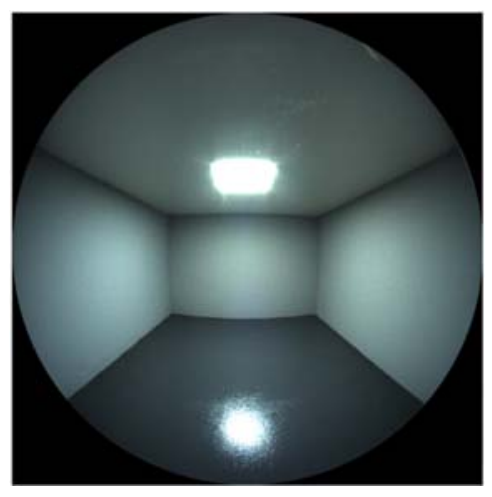

Figure 3 - Inner reference box

\subsection{Experiment in a large office}

The second experiment was done at a large office room whose size is $17.9 \mathrm{~m}$ in width, $12.9 \mathrm{~m}$ in depth and $2.5 \mathrm{~m}$ in height. It had a window whose size is $1.6 \mathrm{~m}$ in width and $1.9 \mathrm{~m}$ in height on the south side. This office was surrounded by high-rise buildings, and the time period when direct sunlight hit the window was limited. The experiment was done when direct sunlight hit the window surface and when it did not. Therefore, the experimental factors and their levels are as follows: 1) Time period in one day -two factors, 2) Venetian blind tilt angle -0 degree/45 degree/closed, 3) Artificial lighting conditions -turn on/off. There were 15 lighting conditions in total. In the large-scale open office, horizontal illuminance on all the desktops and vertical illuminance facing outside at the window were measured at intervals of 5 seconds using Illuminance loggers (TR-74U).

\section{Explanatory variables for spatial brightness formula}

\subsection{Average luminance}

A luminance camera using a circumferential fisheye lens was placed at the viewpoint of the subject, and luminance images was captured at the same time when subject evaluated the light environment. We investigated various spatial brightness formula with one explanatory variable: Average luminance of Ceiling/Walls/Desktop/Whole space, then investigated the formula with two variables: Average luminance of Ceiling/Walls/Desktop/Whole space plus Window luminance. We also investigated the formula with three variables by adding the desktop luminance, however, as the effect of collinearity was observed, this formula was excluded from the investigation. 


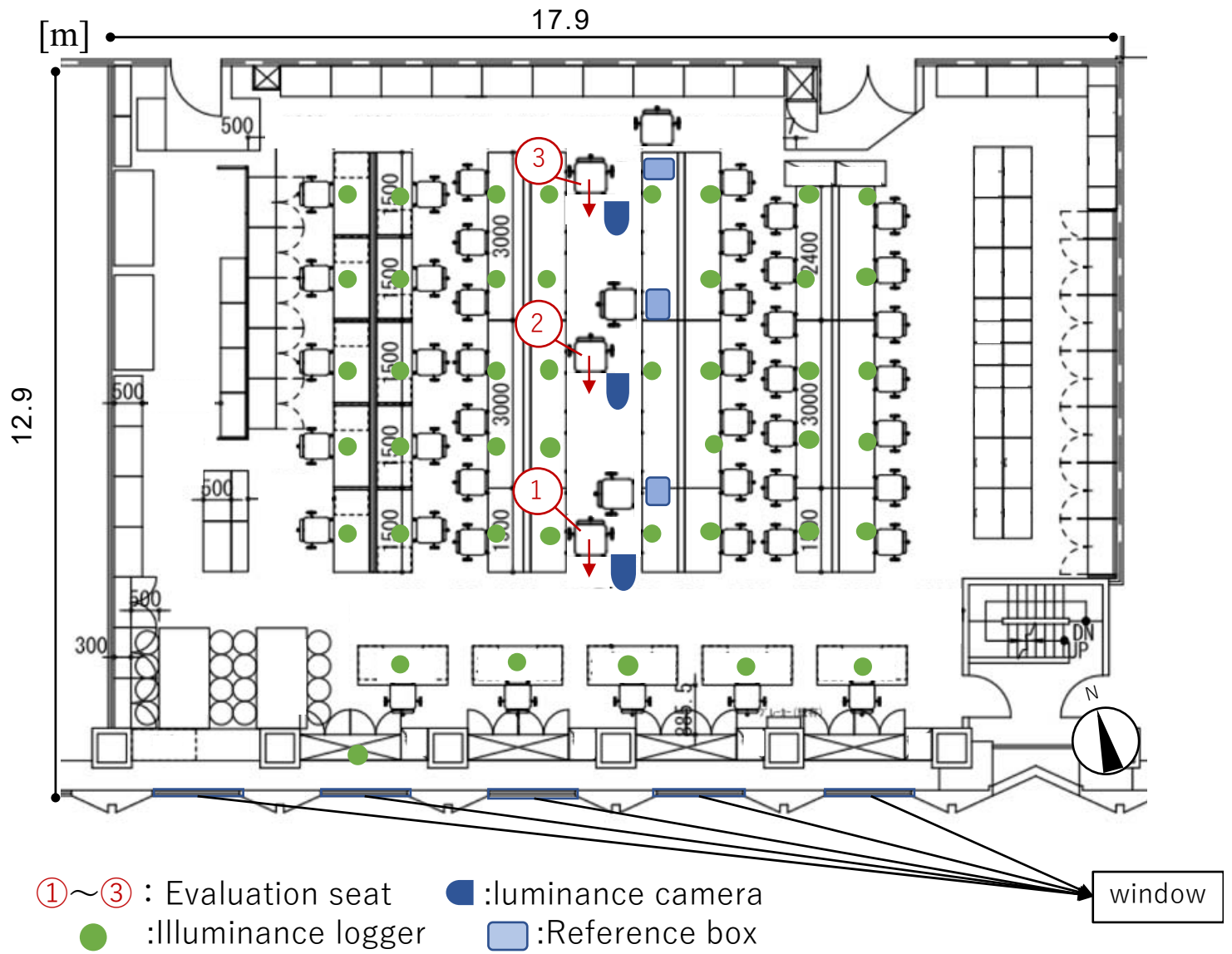

Figure 2 - Drawing of the large office

\section{Explanatory variables for spatial brightness formula}

\subsection{Average luminance}

A luminance camera using a circumferential fisheye lens was placed at the viewpoint of the subject, and luminance images was captured at the same time when subject evaluated the light environment. We investigated various spatial brightness formula with one explanatory variable: Average luminance of Ceiling/Walls/Desktop/Whole space, then investigated the formula with two variables: Average luminance of Ceiling/Walls/Desktop/Whole space plus Window luminance. We also investigated the formula with three variables by adding the desktop luminance, however, as the effect of collinearity was observed, this formula was excluded from the investigation.

In addition, average calculation methods -arithmetic or geometric mean- were also examined in the following process.

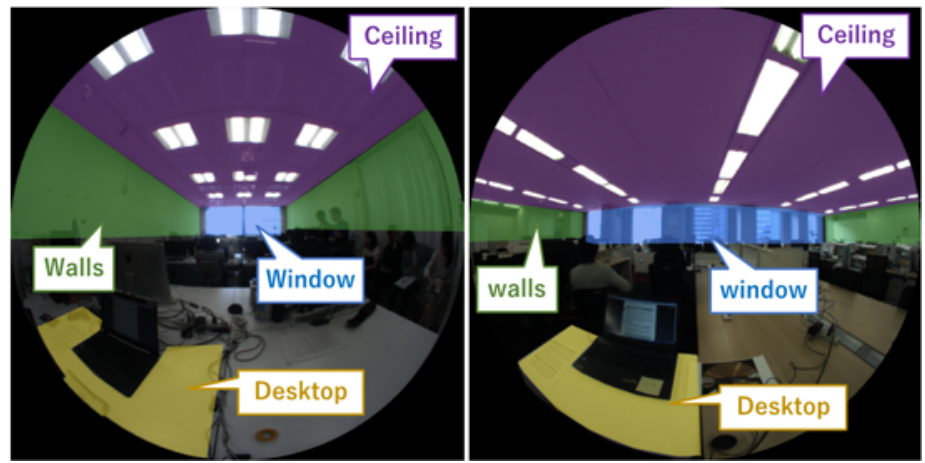

Figure 4 - Reference images: Small office(left) and Large office(right) 


\subsection{Apparent size}

We also took into account the influence of the apparent size of the area, investigating the various formula with explanatory variables: average luminance only, average luminance multiplied by solid angle of the area and average luminance multiplied by the configuration factor (solid angle projection rate) of the area.

\section{Analysis results}

\subsection{Formulae with one variable}

$$
B R=A \cdot \log (L \times \omega)+B
$$

where

$$
\begin{array}{ll}
B R & \text { is the estimation value of spatial brightness } \\
L & \text { is the average luminance } \\
\omega & \text { is the apparent size }
\end{array}
$$

Figure 5 shows that the coefficient of determination is high $\left(\mathrm{R}^{2}=0.93\right)$ when spatial brightness is estimated by the arithmetic average of luminance in the whole space. However, this analysis includes the conditions in the large office where artificial lightings were all turned off and illuminance on the desktops was around $40 \mathrm{Ix}$. This is not the normal light environment in offices. Therefore, we excluded these conditions in the following analyses.

Table1 shows the coefficients of determination of the estimation formula with one variable using Equation (1). When comparing the arithmetic mean and the geometric mean, most of the coefficients of determination in estimation formula using the arithmetic mean were higher than those using the geometric mean.

Spatial brightness in nighttime can be well explained by using the estimation formula exclusive for the nighttime. For the daytime, an estimation formula using explanatory variable of average luminance multiplied by solid angle of the ceiling had the highest coefficients of determination $\left(R^{2}=0.67\right)$.

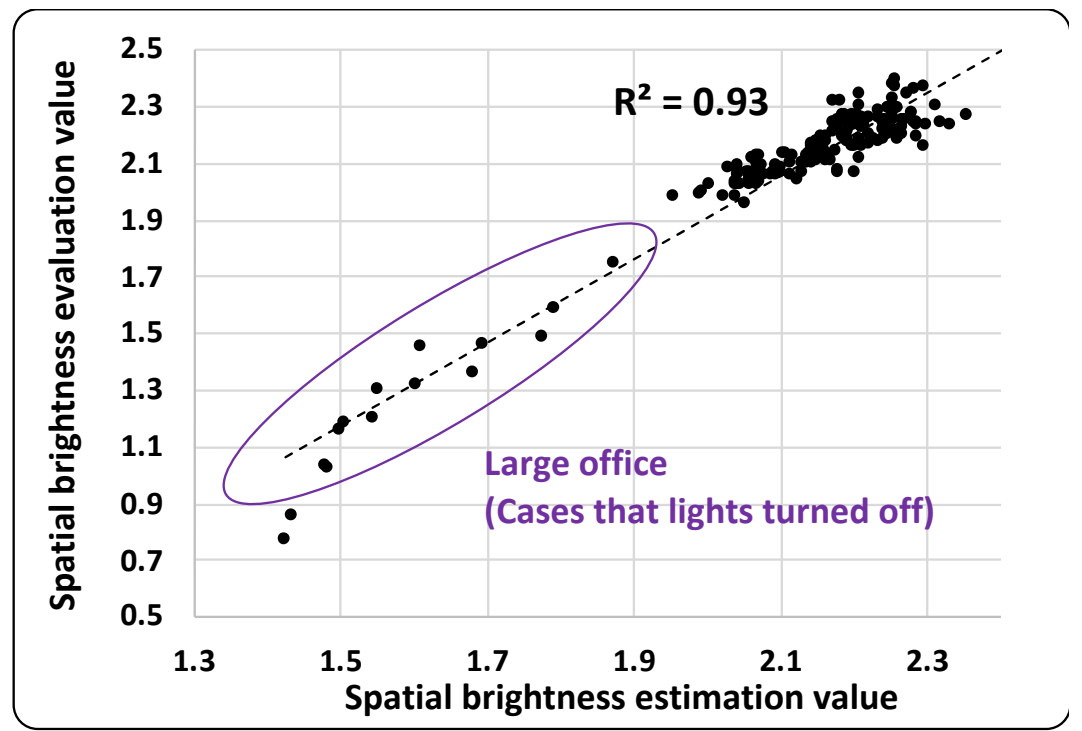

Figure 5 - Spatial brightness estimation: Arithmetic average of luminance of the whole space_including all conditions 
Table 1 - Coefficients of determination when using one variable

\begin{tabular}{|c|c|c|c|c|c|c|c|}
\hline & Average method & Arithmetic & & & Geometric & & \\
\hline Space and Time & Area $\quad \begin{array}{r}\text { Apparent } \\
\text { Size }\end{array}$ & Iuminance only & Solid angle & $\begin{array}{l}\text { Configuration } \\
\text { Factor }\end{array}$ & luminance only & Solid angle & $\begin{array}{l}\text { Configuration } \\
\text { Factor }\end{array}$ \\
\hline \multirow{5}{*}{$\begin{array}{l}\text { Small/Large Office } \\
\text { (Excluding the case that } \\
\text { lights turned off) } \\
\text { Daytime/Nighttime }\end{array}$} & window & 0.08 & 0.06 & 0.13 & 0.13 & 0.11 & 0.20 \\
\hline & ceiling & 0.43 & 0.43 & 0.41 & 0.54 & 0.63 & 0.60 \\
\hline & walls & 0.69 & 0.02 & & 0.66 & 0.01 & \\
\hline & desktop & 0.63 & 0.15 & & 0.58 & 0.09 & \\
\hline & whole space & 0.70 & 0.70 & & 0.43 & 0.43 & \\
\hline \multirow{5}{*}{$\begin{array}{l}\text { Small/Large Office } \\
\text { (Excluding the case that } \\
\text { lights turned off) } \\
\text { Daytime }\end{array}$} & window & 0.04 & 0.03 & 0.09 & 0.11 & 0.10 & 0.18 \\
\hline & ceiling & 0.60 & 0.67 & 0.65 & 0.48 & 0.61 & 0.58 \\
\hline & walls & 0.63 & 0.03 & & 0.66 & 0.03 & \\
\hline & desktop & 0.63 & 0.19 & & 0.58 & 0.10 & \\
\hline & whole space & 0.66 & 0.66 & & 0.60 & 0.60 & \\
\hline \multirow{5}{*}{$\begin{array}{l}\text { Small/Large Office } \\
\text { Nighttime only }\end{array}$} & window & 0.32 & 0.15 & 0.41 & 0.24 & 0.10 & 0.36 \\
\hline & ceiling & 0.69 & 0.63 & 0.61 & 0.84 & 0.82 & 0.76 \\
\hline & walls & 0.92 & 0.00 & & 0.73 & 0.02 & \\
\hline & desktop & 0.92 & 0.03 & & 0.88 & 0.03 & \\
\hline & whole space & 0.86 & 0.86 & & 0.15 & 0.15 & \\
\hline
\end{tabular}

\subsection{Formula using two variables}

$$
B R=A \cdot \log (L a \times \omega a)+B \cdot \log (L b \times \omega b)+C
$$

where

$\boldsymbol{B} \boldsymbol{R}$ is spatial brightness estimation value

$\boldsymbol{L} \boldsymbol{a} \boldsymbol{L} \boldsymbol{b}$ is the average luminance

$\omega \boldsymbol{a} \omega \boldsymbol{b}$ is the solid angle

In order to improve the reliability of the estimation formula, the estimation formulae with two variables: the ceiling surface luminance and the window surface luminance, were examined. However, as shown in Table 2, the coefficients of determination in Daytime were still not high enough.

Table 2 - Coefficients of determination when using two variables

\begin{tabular}{|c|c|c|c|c|c|c|}
\hline \multirow[b]{2}{*}{ Space and Time } & \multicolumn{3}{|l|}{ Arithmetic } & \multicolumn{3}{|l|}{ Geometric } \\
\hline & $\begin{array}{l}\text { luminance } \\
\text { only }\end{array}$ & Solid angle & $\begin{array}{l}\text { configuration } \\
\text { Factor }\end{array}$ & $\begin{array}{l}\text { luminance } \\
\text { only }\end{array}$ & Solid angle & $\begin{array}{l}\text { configuration } \\
\text { Factor }\end{array}$ \\
\hline $\begin{array}{l}\text { Small/Large Office } \\
\text { (Excluding the case that lights turned off) } \\
\text { Daytime }\end{array}$ & 0.61 & 0.67 & 0.65 & 0.48 & 0.61 & 0.60 \\
\hline $\begin{array}{l}\text { Small/Large Office } \\
\text { (Excluding the case that lights turned off) } \\
\text { Daytime/Nighttime }\end{array}$ & 0.50 & 0.53 & 0.52 & 0.55 & 0.66 & 0.64 \\
\hline $\begin{array}{l}\text { Small/Large Office } \\
\text { Nighttime only }\end{array}$ & 0.76 & 0.76 & 0.65 & 0.84 & 0.85 & 0.78 \\
\hline
\end{tabular}

\subsubsection{Absolute value of the window surface luminance}

The analysis by the small office data, the coefficients of the window luminance variable was different among the estimation formulae in the morning and afternoon, and it was negative in the morning when direct sun reached the eastern window. In the large office, the coefficients of the window luminance variable in the estimation formula was also negative when the analysis was conducted only using the data when direct sun reached the windows. Therefore, we decided to divide the data into two groups at a certain absolute value of the window luminance. 
The threshold of the window luminance value was examined comparing the coefficients of determination of estimation formulae. As shown in Table 3, when the data was divided into two groups at the window luminance $1500 \mathrm{~cd} / \mathrm{m}^{2}$, the coefficients of determination of estimation formula of one group less than $1500 \mathrm{~cd} / \mathrm{m}^{2}$ and of other group more than or equal to $1500 \mathrm{~cd} / \mathrm{m}^{2}$ are both relatively high. Coefficients of the window luminance variable in the estimation formula of the group less than $1500 \mathrm{~cd} / \mathrm{m}^{2}$ was 0.29 and -0.24 for the group more than or equal $1500 \mathrm{~cd} / \mathrm{m}^{2}$. This result indicates that, when window luminance is high, it makes the spatial brightness lower.
Table 3 - Comparison of the Coefficients of determination

\begin{tabular}{|c|c|c|}
\hline $\begin{array}{l}\text { Luminance } \\
\text { value }\end{array}$ & Less than & $\begin{array}{l}\text { More than or } \\
\text { equal to }\end{array}$ \\
\hline 1350 & 0.75 & $\begin{array}{r}0.44 \\
\end{array}$ \\
\hline 1400 & 0.75 & 0.44 \\
\hline 1450 & 0.74 & 0.45 \\
\hline 1500 & 0.74 & 0.78 \\
\hline 1600 & 0.72 & 0.81 \\
\hline 1650 & 0.7 & 0.74 \\
\hline 1700 & 0.7 & 0.75 \\
\hline 1750 & 0.69 & 0.9 \\
\hline
\end{tabular}

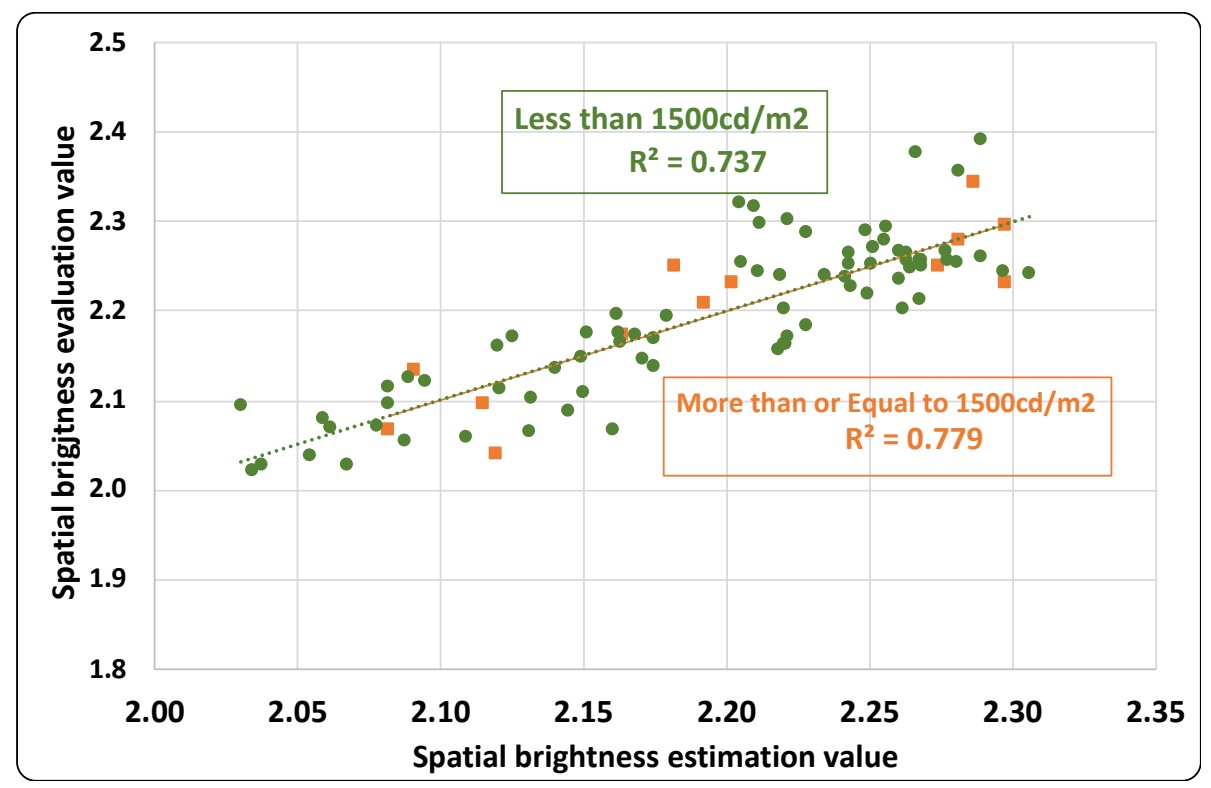

Figure 6 - Plots of the estimation and evaluation values (border: window luminance $1500 \mathrm{~cd} / \mathrm{m}^{2}$ )

Window luminance: more than or equal to $1500 \mathrm{~cd} / \mathrm{m}^{2}$

$$
B R=-0.24 \cdot \log (L w \times \omega w)+0.52 \cdot \log (L c \times \omega c)+1.69
$$

Window luminance: less than $1500 \mathrm{~cd} / \mathrm{m}^{2}$

$$
B R=0.29 \cdot \log (L w \times \omega w)+0.41 \cdot \log (L c \times \omega c)+1.34
$$

\subsubsection{Luminance ratio: Window luminance divided by Ceiling luminance}

As mentioned above, spatial brightness in nighttime can be well explained by using the estimation formula exclusive for the nighttime. Therefore, we decided to divide the data again at the luminance ratio (window surface luminance divided by ceiling surface luminance) was 1.

As shown in Figure 7, the coefficients of determination of the estimation formulae became high for both groups. Coefficients of the window luminance variable in the estimation formula of the group less than 1 of luminance ratio was 0.114 and 0.027 for the group more than or equal 1 of luminance ratio \& less than $1500 \mathrm{~cd} / \mathrm{m}^{2}$ of window luminace. 


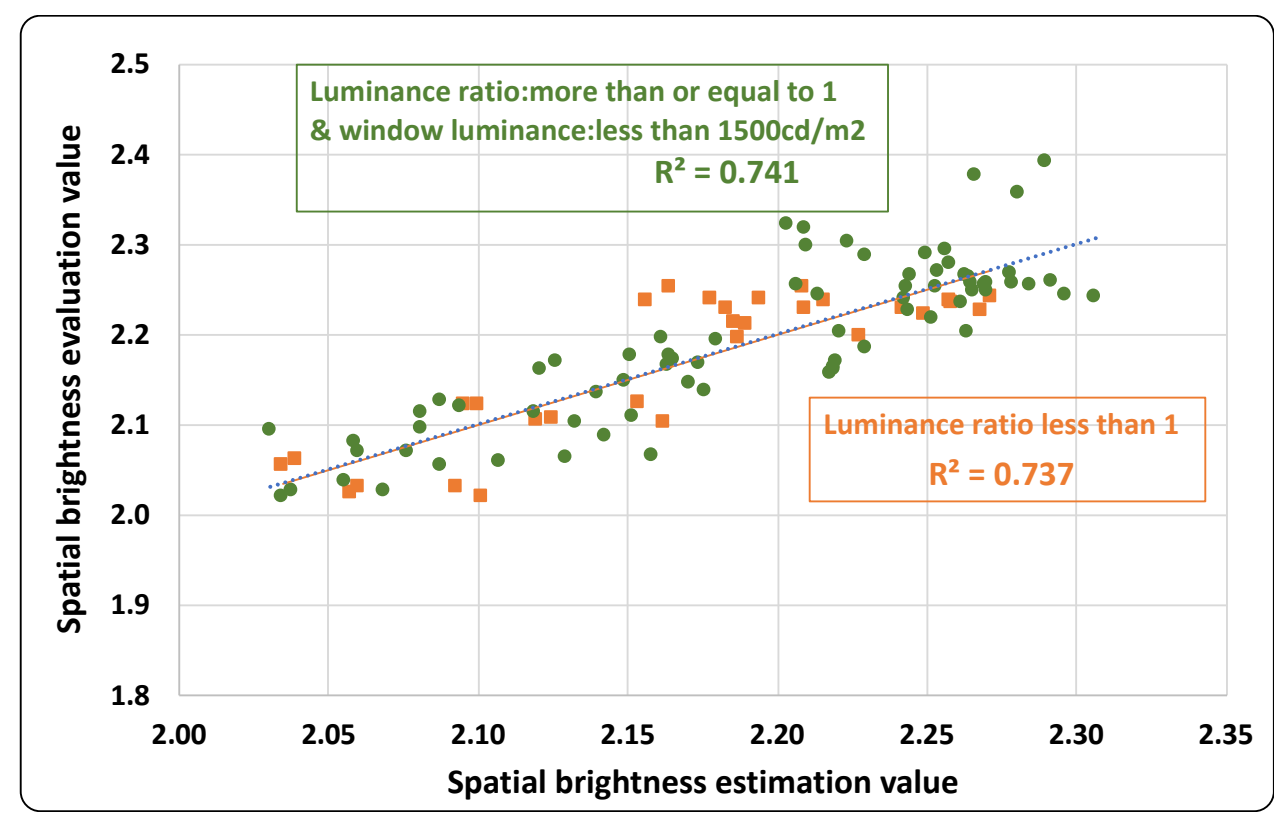

Figure 7 - Plots of the estimation and evaluation values (border: luminance ratio 1)

Luminance ratio: more than or equal to $1 \&$ window luminance: less than $1500 \mathrm{~cd} / \mathrm{m} 2$

$$
B R=0.027 \cdot \log (L w \times \omega w)+0.42 \cdot \log (L c \times \omega c)+1.34
$$

\section{Luminance ratio: less than 1}

$$
B R=0.114 \cdot \log (L w \times \omega w)+0.147 \cdot \log (L c \times \omega c)+1.82
$$

\subsection{Spatial brightness estimation formula for offices with windows}

As a result of the analysis of this experiment, following three formulae were obtained.

Window luminance: more than or equal to $1500 \mathrm{~cd} / \mathrm{m}^{2}$

$$
B R=-0.24 \cdot \log (L w \times \omega w)+0.52 \cdot \log (L c \times \omega c)+1.69
$$

Luminance ratio: more than or equal to $1 \&$ window luminance: less than $1500 \mathrm{~cd} / \mathrm{m} 2$

$$
B R=0.027 \cdot \log (L w \times \omega w)+0.42 \cdot \log (L c \times \omega c)+1.34
$$

\section{Luminance ratio: less than 1}

$$
B R=0.114 \cdot \log (L w \times \omega w)+0.147 \cdot \log (L c \times \omega c)+1.82
$$

\section{Conclusion}

In this research, aiming at developing a new daylight harvesting system, we examined the estimation formulae of spatial brightness in offices with windows. It was shown that, when the window luminance exceeded $1500 \mathrm{~cd} / \mathrm{m}^{2}$, windows had a negative effect on the spatial brightness. Besides, spatial brightness in nighttime can be well explained by using the estimation formula exclusive for the nighttime, and the luminance ratio (window surface luminance divided by ceiling surface luminance) 1 could be the border between daytime and nighttime. This result was obtained from the subjective experiments conducted at only two offices. Therefore, further studies will be necessary to reach more reliable and general conclusions. 


\section{References}

Kazuyoshi, H. 2017. Development of daylighting control method with brightness in office space. Summaries of technical papers of Annual Meeting, Architectural Institute of Japan, 523526.

Naoya, H. 2007. Examination of the validity of various brightness indexes based on the brightness rating in the room which has a scene through the window. Summaries of technical papers of Annual Meeting, Architectural Institute of Japan, 9-14 